\title{
Urdimento
}

Revista de Estudos em Artes Cênicas

E-ISSN: 2358.6958

\section{Para se pensar uma representatividade negra: reflexões sobre o corpo (não) negro nas artes cênicas}

Conrado Dess

\section{Para citar este artigo:}

DESS, Conrado. Para se pensar uma representatividade negra: reflexões sobre o corpo (não) negro nas artes cênicas. Urdimento, Florianópolis, v. 3, n. 39, nov./dez. 2020.

DOI: http:/dx.doi.org/10.5965/14145731033920200204 
Para se pensar uma representatividade negra: reflexões sobre o corpo (não) negro nas artes cênicas ${ }^{1}$

Conrado Dess ${ }^{2}$

\begin{abstract}
Resumo
O autor propõe uma reflexão acerca das transformações sociais que levaram ao surgimento de um movimento que luta por representatividade negra nas artes cênicas nos últimos anos. A partir de uma observação de alguns dos modos como o corpo negro é representado em cena, em particular no espetáculo Entrevista com Stela do Patrocínio, pretende-se realizar uma reflexão sobre as implicâncias políticas e sociais causadas pela presença e pela ausência do corpo negro na cena.
\end{abstract}

Palavras-chave: Representação. Representatividade. Corpo negro. Teatro negro.

Thinking about black representativeness: reflections on the (non) black body in the performing arts

\begin{abstract}
The author proposes a reflection on the social changes that led to the emergence of a movement that advocates for black representation in the performing arts field in recent years. Based on an analysis of some of the ways in which the black body is represented in the scene, especially in the play Entrevista com Stela do Patrocínio, this article also aims to reflect on the political and social implications caused by the presence and the absence of the black body in the contemporary theater scene.
\end{abstract}

Keywords: Representation. Representativeness. Black body. Black theater.

Pensando en una representatividad negra: reflexiones sobre el cuerpo (no) negro en las artes escénicas

\title{
Resumen
}

El autor propone una reflexión sobre las transformaciones sociales que llevaron al surgimiento de un movimiento que busca representatividad negra en las artes escénicas en los últimos años. Tras un análisis de algunas de las formas en que se representa el cuerpo negro en la escena, especialmente en la obra Entrevista com Stela do Patrocínio, el objetivo es también reflexionar sobre las implicaciones políticas y sociales generadas por la presencia y ausencia del cuerpo negro en la escena.

Palabras clave: Representación. Representatividad. Cuerpo negro. Teatro negro.

\footnotetext{
Este texto é desdobramento da pesquisa "Representações e representatividade: possibilidades de uma trajetória em direção ao Outro” financiada pela Fapesp através do processo no 2018/26186-7, Fundação de Amparo à Pesquisa do Estado de São Paulo (FAPESP).

2 Diretor e dramaturgo. Mestrando do Programa de Pós-Graduação em Artes Cênicas da Universidade de São Paulo. conradodess@usp.br
} 
Permita que eu fale, não as minhas cicatrizes Elas são coadjuvantes, não, melhor, figurantes, que nem devia 'tá aqui

Permita que eu fale, não as minhas cicatrizes Tanta dor rouba nossa voz, sabe o que resta de nóiz? Alvos passeando por aí

Permita que eu fale, não as minhas cicatrizes Se isso é sobre vivência, me resumir a sobrevivência É roubar o pouco de bom que vivi Por fim, permita que eu fale, não as minhas cicatrizes Achar que essas mazelas me definem, é o pior dos crimes É dar o troféu pro nosso algoz e fazer nóiz sumir

(Emicida)

Quando nos voltamos brevemente para a história do teatro brasileiro, partindo do teatro jesuítico, passando pelos períodos romântico e realista, pelo teatro de revista, pela cena modernista dos anos 1920, pelas produções politizadas das décadas de 1960 e 1970, até o advento da cena performativa contemporânea, podemos vislumbrar um panorama do modo como a cena de cada período se manifesta como um reflexo da estreita relação que se estabelece entre o teatro e seu tempo presente. Se há dez anos pouco se falava sobre a necessidade de uma cena representativa, hoje, a luta por representatividade em todas as esferas da vida social já se configura não apenas como uma demanda muito bem consolidada, mas, sobretudo, como um dos grandes pontos nevrálgicos das relações políticas e sociais do século XXI.

Segundo Rosane Borges ${ }^{3}$ (2019), podemos compreender o século XIX como o período da história em que o homem ocidental se estabelece como um sujeito que pensa, vive e se relaciona no mundo por meio de representações. Um tempo no qual o advento da revolução tecnocientífica trouxe consigo o vislumbre de uma noção de progresso e o entusiasmo com uma concepção de humanismo que confiava na civilização, na realização individual e na felicidade. Ainda segundo a autora, no século XX, porém, tal esperança e entusiasmo percebem-se destroçados pela brutalidade de duas grandes guerras e pelo decorrente

${ }^{3}$ Rosane Borges é jornalista, doutora em Ciências da Comunicação e pesquisadora nas áreas de comunicação, política contemporânea e relações raciais e de gênero. É articulista do blog da Editora Boitempo e colunista da revista Isto é. Publicou diversos livros abordando temas como racismo, imaginários sociais e representações de mulheres negras. 
ressurgimento da barbárie, escancarando, por fim, a difícil noção de que "o projeto de modernidade carrega em seu germe a ideia de perpétua crise, que se fez sentir por todos os terrivelmente outros, não contemplados por uma concepção de humano e humanismo: negros, indígenas, asiáticos e africanos." (Borges, 2019, p. 10).

É sobre os destroços desse período que surge uma nova compreensão de subjetividade que é marcada por um processo de ruptura na forma como pensamos e enxergamos o mundo. De súbito, encontramos cada vez mais dificuldades em processar as experiências advindas dos horrores de um mundo fragmentado, marcado pela violência das guerras, pelas injustiças sociais e pela aridez de um modelo capitalista pautado na exploração irrefreável do outro. Assim, passamos a encontrar enormes dificuldades em pensar e nos relacionar por meio de representações.

Tais dificuldades se confluem naquilo que, segundo Ileana Diéguez (2016), pode ser compreendido como uma "crise da representação", que acaba por afetar diversas ordens de nossa existência, como a política, a economia, a religião, a cultura, a arte e o próprio campo das ideias. Segundo a autora, essa não é, no entanto, uma constatação recente, mas uma temática que já vem sendo abordada há vários anos por inúmeros autores do campo da filosofia, como Lefebvre, Grüner e Derrida. Segundo Sánchez (2014), uma crise da representação se vincularia, por sua vez, às dificuldades que encontramos em dar forma a um mundo estilhaçado por incoerências e contradições e que se encontra, portanto, à beira do irrepresentável.

É no bojo dessa crise da representação que o teatro vem, desde a segunda metade do século XX, experimentando novos modelos que não buscam apenas formas de representação que se estabeleçam em maior diálogo com o tempo presente, mas que pretendem, sobretudo, expor as rachaduras de um modelo que se converteu arcaico. Desde os elementos advindos da performance arte e que centralizam hoje a noção de teatro performativo, como a transformação do ator em performer, a descrição dos acontecimentos da ação cênica e o alinhamento do espetáculo em torno da imagem e da ação (Féral, 2015), até diversas outras 
experimentações que, ao longo da última década, buscaram colocar o espectador em confronto direto com as questões tratadas na cena (Fernandes, 2013), foram muitas as tentativas de se fazer com que o teatro se mantivesse como uma força operante no processo de construir, organizar e renovar as ordens representacionais que moldam nossa vida social.

Ainda que tais experiências cênicas tenham encontrado terreno fértil para a problematização de antigas práticas representacionais que já não se mostravam mais capazes de abarcar as complexidades de um sujeito racional que se percebe diante de uma crise, não podemos afirmar que tais experimentações tenham obtido muito sucesso, nesse sentido, quando se leva em consideração a experiência do sujeito negro na vida e na cena.

Fruto de um processo de redução do corpo e do ser a uma questão de cor, de destituição do controle de sua própria imagem e das ordens de representação que moldam sua existência, o sujeito negro vive uma crise das representações desde a sua constituição, como exemplifica o relato da autora bell hooks ${ }^{4}(2019$, p. 35):

Me dei conta de que, para as pessoas negras, a dor de aprender que não podemos controlar nossas imagens, como nos vemos ou como somos vistos, é tão intensa que isso nos estraçalha. Isso destrói e arrebenta as costuras de nossos esforços de construir o ser e nos reconhecer. Com frequência, ficamos devastados pela raiva reprimida, nos sentimos exaustos, desesperançados e, às vezes, simplesmente de coração partido.

Considerando que o século XXI possa começar a ser compreendido como um período marcado por embates na ordem do imaginário (Borges, 2019), torna-se inevitável que sejam mais atentamente observadas as imagens, símbolos e construções que orientam nossas relações políticas e sociais. Pela imensa capacidade da linguagem teatral de atuar na esfera do sensível ${ }^{5}$, tais elementos

${ }^{4}$ Batizada como Gloria Jean Watkins, a autora estadunidense bell hooks adotou o nome pelo qual é conhecida em homenagem à sua bisavó, Bell Blair Hooks, uma mulher indígena. A escolha pela grafia de seu nome em letra minúscula é justificada por seu interesse em dar ênfase ao conteúdo de sua escrita e não à sua pessoa. Formada em literatura inglesa pela Universidade de Stanford, mestre pela Universidade de Wisconsin e doutora pela Universidade da Califórnia, bell hooks é autora de mais de trinta livros dirigidos à discussão sobre raça, gênero e classe e às relações sociais opressivas.

${ }^{5} \mathrm{O}$ termo sensivel é empregado aqui conforme utilizado por Óscar Cornago, que o descreve como o que há 
encontram na cena um espaço de profunda ordenação e sedimentação, podendo tal processo orientar tanto novas ordens de representação mais capazes de abarcar o "mosaico possível de acepções do humano" (Borges, 2019, p. 11) quanto as ruínas de um pensamento excludente e oxidado.

No campo das artes cênicas, uma consciência do fato de que uma crise das representações não é algo novo quando se trata da população negra nos permite a compreensão do recente fenômeno que tem colocado a luta por representatividade como uma das principais demandas levantadas por movimentos sociais, artistas, pesquisadores, espectadores e militantes negros na atualidade.

Dentre as inúmeras ações que atuaram nesse sentido nos últimos cinco anos, podemos destacar aqui a manifestação contra a exibição da obra Exhibit B, do artista sul-africano branco Brett Bailey, na 3a edição da Mostra Internacional de Teatro de São Paulo, em 2016. O trabalho, que utiliza atores negros para recriar imagens reais de violência racial, tornou-se o centro de um intenso debate capitaneado principalmente por artistas e ativistas ligados ao movimento negro justamente por reiterar imagens de dominação. A obra teve sua exibição na Mostra cancelada, segundo os organizadores, por questões orçamentárias. Outro evento significativo foram as manifestações contra a utilização do recurso do blackface no espetáculo $A$ mulher do trem, do grupo Os Fofos Encenam, que seria reapresentado anos após sua estreia no Itaú Cultural, em 2015. No espetáculo, um ator branco com o corpo pintado de preto interpretava de maneira cômica uma empregada doméstica negra. O uso do artifício considerado racista levou ao cancelamento da apresentação e a posterior realização de um debate sobre a questão.

Possível reflexo de uma compreensão de que o século XXI também está sendo marcado por uma sede de representação e visibilidade daqueles historicamente subalternizados (Borges, 2019), tais manifestações podem ser

no meio, o que ocupa o espaço que está entre um objeto e uma pessoa ou entre uma pessoa e outra. Segundo o autor, é o lugar do imaginário, onde nossas formas de estar, relacionar e projetar-nos se oferecem aos sentidos (2015). 
entendidas como a erupção de um processo que materializa o negro como um "sujeito de luta" (Azevedo, 2018) e que reitera, também nas artes cênicas, a percepção de que, como aponta hooks, tornou-se uma tarefa fundamental para artistas, pesquisadores e pensadores negros críticos pensar e empreender formas de atuação que visam "romper com os modelos hegemônicos de ver, pensar e ser que bloqueiam nossa capacidade de nos vermos em outra perspectiva, nos imaginarmos, nos descrevermos e nos inventarmos de modos que sejam libertadores." (hooks, 2019, p. 32).

Sendo o teatro também um espaço de poder e, sobretudo, uma linguagem que se constitui principalmente através de práticas representacionais imagéticas, há de se considerar um ponto fundamental que centraliza tanto a capacidade da cena de reproduzir modelos hegemônicos quanto de fragilizá-los, tanto a possibilidade do sujeito negro de ser visto em outra perspectiva quanto a capacidade dele próprio de se ver de modos que the sejam libertadores: o olhar.

Quando nos voltamos para tais manifestações, o que testemunhamos é o surgimento do que hooks (2019) define como um olhar negro, um olhar que é insurgente, questionador, desafiador, que não se abaixa mais diante do discurso hegemônico, mas que propõe uma ruptura nos modelos representacionais vigentes ao identificar imagens de dominação, opressão, desumanização ou, até mesmo, de ausência.

É, portanto, no domínio da imagem que o sujeito negro vive sua crise. Seja quando olha para cena e não se vê, seja quando é violentado por uma representação subalternizadora de si ou quando se depara com sua tragédia também fora dos palcos, como descreve hooks:

Vivenciamos nossa crise coletiva como afro-americanos no domínio das imagens. Seja no rosto de moradores de rua encontrados nas metrópoles ou nos becos de cidades pequenas, no olhar perdido dos desempregados, ao ver pessoas que amamos viciadas em drogas, ou alguma cena trágica de um filme que fica na cabeça, nós vemos que estamos com problemas. (hooks, 2019, p. 40).

Se, na perspectiva de hooks, o negro sabe que está com problemas ao se 
deparar com as imagens de uma tragédia social, quando olhamos para o teatro brasileiro percebemos que a tragédia do negro na cena é a ausência, quando não, a total impossibilidade de controle de sua própria imagem.

A constatação de uma carência de representatividade negra nas artes cênicas brasileiras, bem como o surgimento de um olhar insurgente em relação à representação do negro não são, no entanto, processos novos. Ao longo da segunda metade do século XX até os anos mais recentes, foram muitos os grupos e artistas que identificaram a problemática e atuaram em prol da desarticulação dos modelos representacionais hegemônicos através de ações que promoveram a integração do negro na sociedade brasileira, a crítica da ideologia da brancura, a valorização da contribuição negra à cultura brasileira e a produção de uma dramaturgia intrinsecamente negra (Lima, 2011). Dentre esses grupos, o Teatro Experimental do Negro (TEN), fundado em 1944 e capitaneado por Abdias do Nascimento, teve papel significativo. Tendo produzido mais de vinte espetáculos e se mantido ativo continuamente por mais de 15 anos, o TEN abriu caminho para o desenvolvimento de iniciativas semelhantes por todo o país, como: o Teatro Popular Brasileiro, fundado em 1956 por Solano Trindade, no Rio de Janeiro, o Grupo Bambarê - Arte e Cultura Negra, fundado em 1986, em Belém, o Bando de Teatro Olodum, fundado em 1990, em Salvador, a Cia. dos Comuns, fundada por Hilton Cobra, em 2001, no Rio de Janeiro, e, mais recentemente, os diversos novos coletivos formados por jovens artistas negros que surgiram a partir da década de 2000, principalmente na trilha de escolas de teatro, como os grupos Coletivo Negro, Os Crespos, Capulanas Cia. de Arte Negra, Coletivo Preto, Grupo Emú, entre muitos outros.

Considerando esse panorama histórico, o que podemos identificar em eventos como a manifestação contra a obra do sul africano Brett Bailey e contra o uso do blackface no espetáculo do grupo Os Fofos Encenam, é o surgimento de uma nova onda de olhares insurgentes direcionados às artes cênicas que se mobilizam principalmente através das redes sociais e que, dessa vez, não se limitam essencialmente às perspectivas de artistas negros e seu entorno, mas que abarcam também os mais diversos grupos da sociedade, como espectadores, 
jornalistas, militantes, educadores e integrantes de movimentos sociais. Olhares que, dessa vez, não se desdobram prioritariamente em ações de valorização da cultura negra, mas também, em denúncias e no desmantelamento de obras e ações que atuam no sentido oposto.

Dentre tais manifestações, outra que podemos destacar aqui é o evento envolvendo o espetáculo Entrevista com Stela do Patrocínio. No ano de 2017, quase doze anos após sua estreia, o espetáculo criado pelo Núcleo do Cientista, no qual a atriz branca Georgette Fadel interpreta a poeta negra Stela do Patrocínio, receberia uma crítica que modificaria substancialmente - e encerraria - sua trajetória ${ }^{6}$. Durante a primeira de quatro apresentações que seriam realizadas em uma curta temporada na Biblioteca Mário de Andrade, no centro de São Paulo, uma voz em meio a plateia bradou: o Egito era negro! Georgette Fadel era, naquele momento, criticada por um jovem negro pelo fato de ser uma artista branca representando uma pessoa negra, ou em outros termos, uma voz historicamente opressora que se utilizava de uma voz historicamente oprimida em prol de seu fazer artístico.

Após a intervenção feita pelo jovem, Georgette decidiu continuar a apresentação depois de uma breve pausa e, ao final do espetáculo, abriu espaço para um debate, convidando o jovem que havia se manifestado e sua então companheira, a ex-artista Danielle Cristine $^{7}$, a apresentarem seus pontos de vista sobre a obra.

Após esse evento, seguiram-se dias de intensos debates nas redes sociais, jornais e rodas de conversa, muitos deles classificando a ação da dupla como desrespeitosa e autoritária. De acordo com Georgette, o que a fala de Danielle ao final da apresentação apontou, no entanto, foi a falta de uma perspectiva racial na representação de Stela do Patrocínio, poeta negra, pobre, portadora de

\footnotetext{
${ }^{6}$ Em dezembro de 2020, parte do grupo ligado ao espetáculo original, juntamente com outros artistas, estrearam um experimento cênico/sonoro a partir da vida e obra poética de Stela do Patrocínio e das músicas originais do espetáculo Entrevista com Stela do Patrocínio. O experimento Stelas Pretas - claridade e luz conta com a presença das atrizes negras Mawusi Tulani e Nilcéia Vicente e tem direção musical e música de Lincoln Antônio e orientação de cena e dramaturgia de Georgette Fadel.
}

${ }^{7}$ Em entrevista que me foi concedida, Danielle Cristine manifestou seu desejo em ser referida com ex-artista. 
esquizofrenia, que viveu por 30 anos internada na Colônia Juliano Moreira, no Rio de Janeiro:

[A Danielle disse:] Em nenhum momento no seu espetáculo você fala que ela foi estuprada por ser negra, por ser doméstica, e você vai enfatizar o tema da loucura, só que essa loucura tem raça, essa loucura tem classe e isso está abandonado no espetáculo, a não ser no final, quando você cita que ela é negra. A gente pensa que ela é uma louca, uma dissociada, inteligente, com profundidade, mas, mesmo assim, isso não é central. E é central. É justamente a questão. (Fadel. Informação verbal) ${ }^{8}$.

Diante desse complexo cenário, há de se considerar a importância do fato de que o ator negro Ney Mesquita, que idealizou o projeto e interpretaria Stela, faleceu antes de sua estreia definitiva, sendo substituído por Georgette ${ }^{9}$. Tal intercorrência, a substituição de um ator negro por uma atriz branca, trouxe por sua vez, importantes desdobramentos no campo da representação quando se considera a questão da representatividade.

Visto que essa compreensão nos requer uma reflexão sobre alguns dos modos como o corpo negro se manifesta no mundo e na cena, consideraremos aqui as elaborações empreendidas pelo teórico camaronês Achille Mbembe no livro Crítica da Razão Negra (2018). Na obra, o termo "negro" é descrito como produto de um maquinário técnico e social intrinsicamente ligado às demandas do sistema capitalista, um termo que foi criado com o fim de significar "exclusão, embrutecimento e degradação, ou seja, um limite sempre conjurado e abominado" (Mbembe, 2018, p. 21). Para o autor, num plano fenomenológico, o termo não designa uma realidade significante, mas "um rebotalho de disparates e da fantasia que o Ocidente (e outras partes do mundo) urdiu e com o qual recobriu as pessoas de origem africana muito antes de serem capturadas nas redes do capitalismo

\footnotetext{
${ }^{8}$ Entrevista não publicada me concedida por Georgette Fadel. São Paulo, março de 2019.

${ }^{9}$ A substituição de um ator por uma atriz poderia sugerir a subversão de um outro tipo de representatividade, uma vez que, com a atuação de Ney Mesquita, uma mulher estaria sendo representada por um homem. No entanto, entende-se aqui que a questão da representatividade cisgênera nas artes cênicas estaria em um estágio social e político muito mais avançado quando comparada com a representatividade de minorias sociais, não implicando, portanto, em comprometimentos éticos do discurso de Stela no espetáculo. Uma reflexão apropriada sobre a questão da representatividade de gênero requereria, no entanto, um estudo aprofundado que não é possível de ser desenvolvido aqui, uma vez que o foco deste artigo é a representatividade negra.
} 
emergente dos séculos XV e XVI" (Mbembe, 2018, p. 80).

Ainda na perspectiva de Mbembe, esse imenso rebotalho de disparates, fantasmas e mentiras acabou se fixando como uma espécie de invólucro externo cuja função primordial foi substituir o ser humano negro, sua vida, seu trabalho e sua linguagem. Como revestimento exterior, esse invólucro se estratificou, transformando-se em um conjunto de membros e acabando por se tornar, com o passar do tempo, uma casca calcificada, uma segunda ontologia ou uma chaga; ferida viva que corrói, devora e destrói todos os que acomete (Mbembe, 2018).

Nessa compreensão, o sujeito negro dificilmente consegue se esconder ou escapar do olhar que o fixa, que o nega, que o destrói e o reconstrói como uma fantasmagoria, visto que seu corpo é constantemente submetido às percepções moldadas por um invólucro que chega antes dele mesmo e que, em um processo de desumanização, o esvazia de sua subjetividade para preenchê-lo com fantasmas, mentiras e disparates.

Apesar desse processo de fixação a que foi submetido, o negro, no entanto, foi capaz de "dar a volta" nesse olhar que o objetificou, transformando essa casca calcificada em uma pulsão vital, em vórtex de energia capaz de distorcer tudo que está a seu redor e de criar novos e humanizantes significantes a tudo que the é atrelado:

Numa reviravolta espetacular, [o negro] se tornou o símbolo de um desejo consciente de vida, força pujante, flutuante e plástica, plenamente engajada no ato de criação e até mesmo no ato de viver em vários tempos e várias histórias simultaneamente. Sua capacidade de fascinação, ou mesmo de alucinação, não fez senão se multiplicar. Alguns nem sequer hesitariam em reconhecer no negro o limo da terra, o veio da vida, por meio do qual o sonho de uma humanidade reconciliada com a natureza, com a plenitude da criação, voltaria a ganhar cara, voz e movimento. (Mbembe, 2018, p. 21).

A essa perspectiva, é preciso somar ainda, a compreensão empreendida pelo professor e diretor teatral José Fernando Peixoto de Azevedo, que afirma que, para além da fórmula ultimamente retomada, segundo a qual o negro como "raça" é uma invenção do capitalismo, o negro é, depois disso: 
Sujeito de uma posição no mundo. A palavra "negro" não designa apenas a vítima, mas também aquele que se afirma sujeito de luta, forma radical de uma consciência em explosão. Antes reificada num processo de destituição dos corpos e das almas, essa consciência projeta-se no tempo, agora, tensionando memória e história. (Azevedo, 2018, p.7).

Desse modo, podemos entender que, quando falamos do sujeito negro hoje, já não falamos mais de um objeto que se constitui unicamente sob um invólucro de disparates, mentiras e fantasmas, mas, sobretudo, de um sujeito que, uma vez fixado nessa posição, foi capaz de desestabilizá-la para emergir enquanto protagonista de sua condição. Falamos, portanto, de um sujeito que se constituiu enquanto força coletiva justamente a partir de sua necessidade de destruir a casca calcificada sob a qual estava fixado.

Assim, ao entrar em cena como Stela do Patrocínio, Ney Mesquita evocava por meio da cor de sua pele, de sua imagem, esse invólucro exterior que denunciava os imaginários subalterizantes aos quais o corpo negro foi atrelado ao longo da história. Ao mesmo tempo, tal processo era também capaz de afirmar a força transformadora desse sujeito, que luta há séculos pelo desmantelamento desse envoltório, materializando na cena não apenas a posição do sujeito negro no mundo, mas também as camadas éticas e políticas que essa presença convoca.

Com efeito, ao representar Stela, Ney Mesquita depositava, a partir de seu próprio corpo, todos esses tecidos sobre a figura da poeta, não sendo, portanto, necessária qualquer citação textual sobre a cor de sua pele para revelar o fundo racial que rondava sua loucura, uma vez que tudo isso já se materializava ali, em sua imagem e em seu ser. No momento em que Georgette Fadel, uma atriz branca, assume o lugar antes ocupado por Ney, esse invólucro se despedaça, ocultando o tensionamento entre história e memória, apagando as humilhações às quais o corpo negro foi submetido e que ainda pulsam como ferida aberta e, especialmente, eclipsando a posição atual do negro enquanto sujeito de luta, bem como o tecido ético e político que a presença de um corpo negro em um espaço de poder é capaz de convocar. 
É, dessa maneira, justamente perante uma experiência cênica contemporânea que emerge enquanto linguagem como resposta a uma crise das representações, mas que paradoxalmente ainda não responde à crise das representações do sujeito negro e de outras minorias que emerge a crítica de Danielle. Ao se deparar com Georgette Fadel, uma atriz branca, representando Stela do Patrocínio, uma mulher negra, Danielle vislumbra um sistema de representação que falha ao tentar representá-la. Sua crítica passa a ser compreendida, assim, como um ato de problematização que visa denunciar uma ordem de representação que se afirma política e transgressora, mas que falha diante da pluralidade e da complexidade do sujeito contemporâneo, que se mostra racista não na intenção particular dos artistas, mas na reprodução de gramáticas de produção hegemônicas.

A intervenção de Danielle e de seu companheiro enfraquece, dessa maneira, o invólucro que sustenta a representação tanto no âmbito da apresentação teatral em si quanto do que o espetáculo pode representar enquanto experiência social. Ao se manifestarem contra a representação de Stela por uma atriz branca, os jovens estilhaçam o ato da representação teatral e fragilizam a moldura de teatralidade que a protege, evidenciando para artistas e espectadores a dimensão pública do teatro. Uma vez colocados em questão, esses imaginários já não podem mais serem negligenciados e tornam-se, desse modo, objetos de um debate público que se instaura justamente em uma compreensão do teatro como prática social.

\section{Corpo negro e representação}

Em seu livro Practising the real on the contemporary stage (2014), o teórico e pesquisador José A. Sánchez destaca como, na língua espanhola, a palavra "representação" engloba vários sentidos que são, muitas vezes, descritos por diferentes palavras em outros idiomas. Por observarmos no português a existência de um paralelo linguístico nesse sentido, empregaremos aqui as distinções elaboradas pelo teórico, que define como representação teatral (1) aquela que se 
refere à mise-en-scène de um trabalho dramático, a uma apresentação; como representação mimética (2) aquela que se define através da imitação, no sentido de colocar a si mesmo no lugar de um outro através de um exercício de construção ou mimeses, o que corresponde ao que os alemães se referem como Darstellung; além dos sentidos de representação como a capacidade de algo ou alguém de representar características comuns de grupo ou comunidade (3), ou de representação no sentido de atuar representando alguém (4), como no sistema político democrático, em que o presidente representa o povo de um país, o que corresponde ao que os alemães chamam de Vertretung.

Nessa perspectiva, o espetáculo Entrevista com Stela do Patrocínio não é representado (1) pois se deseja simplesmente representar (2) Stela, uma mulher negra, mas sim porque se entende que sua história e seu discurso podem ser representativos (3) de questões que permeiam o indivíduo contemporâneo. O espetáculo, no entanto, ao trazer uma mulher branca representando (2) uma mulher negra, faz com que a obra não se torne representativa (3) da população negra, uma vez que no entendimento desse grupo apenas um corpo negro pode atuar como o representante (4) das especificidades e complexidades que determinam sua existência.

Nesse contexto, populações negras têm passado a denunciar esse processo de não-contemplação que muitas vezes se estabelece durante as tentativas de representação (3) do sujeito contemporâneo, especialmente quando tais tentativas utilizam-se de modelos subalternizantes ou apagam a perspectiva racial a fim de tornar esse sujeito universal. Partindo dessa compreensão, outro questionamento também se mostra fundamental: por que a representação mimética (2) se configura hoje como um sistema obsoleto quando se deseja representar (3) grupos sociais minoritários?

Segundo Sánchez (2014), o poder político do teatro - ou da teatralidade — está baseado na transição de Darstellung para Vertretung. Em outras palavras, o teatro adquire força política quando ele é capaz de realizar uma operação em que as ações feitas por um ator/representante (2), ou por seu personagem, se tornam representativas (3) de um povo, transformando esse ator ou personagem, em 
representante (4) do grupo que é ali representado.

Levar a cabo essa operação de "tornar algo ou alguém representativo (3)" demanda, no entanto, que o intérprete, a fim de que aconteça o processo de identificação, seja capaz de "esvaziar-se" de sua individualidade, conforme discorre o autor:

Da mesma forma que nós exigimos de um político ou um representante sindical que ele não se torne um ator ou reivindique representatividade, nós também podemos exigir de um ator que ele não se utilize dos privilégios do palco para se considerar um representante (4) performativo - ou simplesmente representativo (3) de qualquer coisa - sem renunciar a formulação dos discursos. A possibilidade de alguém encenar um Hamlet ou uma Antígona contemporâneos não depende muito de talento artístico, mas da capacidade humana de esvaziar-se da individualidade, de esvaziar-se de expressão para se tornar apenas 'uma pessoa qualquer'. (Sánchez, 2014, p. 161).

Nessa perspectiva, para que uma representação nesses modos se dê, a prática demanda do artista o "sacrifício" da supressão de sua individualidade em prol da construção de uma experiência que possa ser fruída em uma dimensão coletiva:

A possibilidade dessa representação não é encontrada na qualidade específica de um indivíduo ou na articulação precisa de uma ideia, mas sim na capacidade individual de um ator se de esvaziar e de se deixar ser habitado por uma força externa que posteriormente se transmuta em uma força coletiva. (Sánchez, 2014, p. 162).

Na perspectiva desse "exercício de esvaziamento", é impossível, no entanto, ignorar o fato de que a "mediação representativa na área das artes cênicas é ofuscada pelo imediatismo do corpo e pela relação real dos corpos no palco ou em espaços compartilhados de performance com outros corpos participantes ou observadores" (Sánchez, 2014, p. 158), o que faz com que tanto a materialidade do corpo quanto sua imagem se tornem os principais "entraves" quando se fala em uma "neutralidade" que precede a representação:

O corpo é inseparável de sua própria imagem; o corpo é sempre sua própria imagem (Belting, 2001). Apesar disso, essa imagem se torna representação apenas quando ela se livra do corpo que a sustenta, 
quando o corpo se torna ausente ou quando o corpo é privado daquilo que o define como um corpo subjetivo. (Sánchez, 2014, p. 158).

Há de se considerar, contudo, que, na sociedade como a percebemos hoje, alguns corpos são lidos como mais "esvaziáveis" do que outros. A ideia de um corpo que pode se tornar neutro ou suprimido de individualidade para representar uma coletividade só pode, portanto, ser concebida quando consideramos o que é socialmente lido como "neutro", "normal", "ideal" ou "universal", bem como quem faz tais considerações.

Visto que o corpo é sempre a sua própria imagem (Belting, 2001), podemos considerar a cor da pele como um elemento determinante nessa operação. Que corpo é esse que pode ser privado daquilo que o define como um corpo subjetivo? Que imagem é essa que pode se livrar do corpo que a sustenta?

Como já destacamos anteriormente, o corpo negro carrega consigo um invólucro, uma casca calcificada que se faz presente, que se materializa, que o torna identificável justamente por meio da cor de sua pele, ou seja, por meio de sua imagem. Segundo Mbembe (2018), a partir do século XIX, essa casca ganha "existência quase autônoma, funcionando ora como motivo ornamental, ora como a imagem de um duplo e, de modo ainda mais sinistro, uma carcaça - o que sobra do corpo depois de ter sido destrinchado ou desencarnado" (Mbembe, 2018, p. 81). Tal carcaça, opera, portanto, como uma máscara, que não é neutra, mas principalmente ideológica, privando, assim, o corpo das pessoas negras de suas subjetividades e, ao mesmo tempo, evocando todo o imaginário fantasmagórico que determinou a existência do sujeito racializado na modernidade. Nesse sentido, a seguinte fala de Danielle se mostra precisa:

Eu acho louco é que eu não posso fazer qualquer papel no teatro. Não cola. Mesmo que eu queira, que eu faça, ou vai ser risível... Bom, em algum aspecto, dependendo do lugar que eu circular, essa figura não vai colar. A figura que cola para a gente é a figura da empregada, falando de forma mais macro né, não entrando em tipos de teatro, falando de uma forma mais massiva, do que seria conhecido mais popularmente. Eu não poderia escolher qualquer papel para fazer. Por que uma pessoa branca pode 
fazer qualquer papel? (Cristine. Informação verbal) ${ }^{10}$.

Através de um pequeno exercício de imaginação, podemos adentrar na reflexão que Danielle propõe. Popularmente falando, uma atriz negra, quando faz Antígona, não é lida apenas como "uma atriz fazendo Antigona", mas como "uma atriz negra fazendo a Antigona”. Uma atriz negra fazendo Medéia, não é lida como "uma atriz fazendo Medéia", mas como "uma atriz negra fazendo a Medéia". Um casal de atores negros encenando Romeu e Julieta não é lido como um casal de atores encenando o clássico de Shakespeare, mas como um "Romeu e Julieta feito por negros", ou seja, o sujeito negro tende a ser racializado independente do que propõe em termos de imagem e, portanto, de representação.

Assim, quando Danielle afirma que não pode fazer qualquer papel porque simplesmente "não cola" ela se refere à operação em que o invólucro, a máscara fixada ao corpo do negro, atua ideologicamente, impedindo que esse corpo se "esvazie" não de sua subjetividade, uma vez que essa já the foi retirada, mas de seu duplo, de sua fantasmagoria, dificultando que a imagem por ele proposta se livre do corpo que a sustenta para se tornar, finalmente, representação.

O corpo negro, dessa maneira, é um corpo que tende a resistir à representação teatral, justamente por ter sido violentamente convertido em elemento representativo de um imaginário de subalternização. Quando a representação por ele proposta vai ao encontro desse imaginário hegemônico, como no caso da representação de uma empregada doméstica ou de um negro escravizado, essa figura "cola”, ou seja, a representação acontece plenamente. No entanto quando a representação proposta vai em direção oposta, ela torna-se estranha, risível, denunciando a dificuldade do corpo negro de adentrar totalmente no campo da representação.

Ainda que todos os corpos tenham histórias, estigmas, privilégios e contradições e, portanto, tendam a resistir à representação em alguma esfera, podemos notar que, num plano fenomenológico, são os corpos não brancos

${ }^{10}$ Entrevista não publicada me concedida por Danielle Cristine. São Paulo, maio de 2019. 
(negros, indígenas, asiáticos) os que mais padecem de uma "resistência à representação". Tal fato ocorre porque, socialmente, o corpo branco não é racializado e é, portanto, lido como "neutro":

Edith Piza (2002) e Ruth Frankenberg (1999) argumentam que, se há algo característico da identidade racial branca, esta característica é a invisibilidade, que se concretiza diariamente através da falta de percepção do indivíduo branco como ser racializado. A brancura, neste caso, é vista pelos próprios sujeitos brancos como algo "natural" e "normal". (Schucman, 2014, p. 58).

Considerando que o Brasil é uma sociedade constituída no bojo de um sistema escravista pautado justamente na elevação cultural branca, na discriminação e na exploração da população negra, percebemos que a visão da brancura como algo "normal" ou "padrão" não é "apenas" o modo como o sistema da branquitude ${ }^{11}$ se constrói, mas, sobretudo, o modelo representacional que pautou a formação de nossa sociedade, revelando, assim, o quanto a supremacia branca ainda norteia os sistemas de representação do povo brasileiro:

Essa invisibilidade acontece quando uma sociedade chega ao ponto de
uma hegemonia e uma ideia de supremacia branca tão poderosa, em que
os não brancos não têm voz nem poder para apontar a identidade racial
do branco, nem tampouco os brancos conseguem se perceber como
mais uma das identidades raciais, mas sim como a única identidade racial
normal, e outras devem alcançá-la em níveis intelectuais, morais,
estéticos, econômicos, etc. (Frankenberg, 2004, apud Schucman, 2014,
p.58).

Quando Danielle questiona, assim, o porquê de uma pessoa branca poder representar qualquer papel, podemos inferir que é porque o corpo branco, uma vez entendido como "neutro", oferece significativamente menos "resistência à representação", sendo a ele tudo permitido nessa esfera.

É como possibilidade de resistência a esse cenário que emergem ações políticas como a de Danielle e de seu então companheiro, buscando denunciar

${ }^{11}$ O termo é utilizado aqui conforme conceitualizado por Schucman (2014), que afirma que a branquitude foi construída como "um constructo ideológico de poder, em que os brancos tomam sua identidade racial como norma e padrão, e dessa forma outros grupos aparecem, ora como margem, ora como desviantes, ora como inferiores." (Schucman, 2014, p.46). 
sistemas de representação inoperantes e sugerindo estratégias para torná-los mais igualitários. Tais ações visam, em última instância, contribuir para que o invólucro, a máscara ideológica afixada em corpos não brancos seja transcendida, estilhaçada, tornando, assim, todos os corpos "neutros" ou "esvaziáveis" para a representação, pois, apenas no momento em que isso for alcançado, todos os corpos poderão, sob uma perspectiva ética, representar todos os papéis.

Um possivel projeto de reparação poderia também ir no sentido oposto, reforçando a ideia de igualdade social entre os corpos, mas por uma via que não é a de uma neutralidade propriamente dita. Uma vez que a racialização de corpos não brancos é um fato social dado, outras ações poderiam atuar corroborando a perspectiva racial do corpo branco. A partir do momento em que todos os corpos passam a não serem entendidos como "neutros", também seria possível, sob uma perspectiva ética, adentrarmos em uma esfera mais democrática da representação.

É certo que a complexidade do tema e a pluralidade dos sujeitos que sob ele se inserem evidenciam que não há respostas ou saídas fáceis para a questão. Nesse panorama, é necessário destacar também que os pontos de vista de sujeitos negros e brancos são consideravelmente distintos quando se voltam para a questão da representatividade, uma vez que as experiências do sujeito negro são incontornavelmente transpassadas pelo racismo. Como uma tecnologia mutante, o racismo segue em plena operação até os dias de hoje, colocando as ações e o olhar do sujeito negro em uma posição singular, uma vez que "o negro é, na ordem da modernidade, o único de todos os seres humanos cuja carne foi transformada em coisa e o espírito em mercadoria" (Mbembe, 2018, p. 21). Tais constatações nos permitem a compreensão de que as chagas do racismo, ainda que de diferentes formas, são uma experiência comum aos sujeitos negros, independente de nacionalidade ou de classe social, perpassando, assim, toda sua experiência de vida e incidindo justamente no amálgama do sensível que é por ele construído e compartilhado em suas experiências diárias, incluindo aí suas experiências no teatro, seja como artista ou como espectador.

Diante desse contexto, priorizar uma perspectiva política dentro dos 
incontáveis pontos de vista a partir dos quais a questão da representatividade pode ser observada não se trata de uma ação de retaliação, de um projeto de reparação através do cerceamento ou mesmo de uma tentativa de estabelecer novas relações de poder. Tampouco se pretende enfatizar dualidades como o branco vs. o negro, o poder vs. o contrapoder ou subalternizador $v s$. o subalternizado, que por si só podem ser limitadoras, mas sim propor uma ação prática que emerge em caráter de urgência visando garantir o acesso de um determinado grupo social aos espaços de troca que lhe foram historicamente negados, visto que é apenas em um espaço igualitário e democrático que essa discussão pode, antes de tudo, ser uma alternativa possível.

Considerando que cada tempo possui configurações e desafios políticos e sociais específicos, é inegável que a emergência de olhares insurgentes em todas as esferas da vida social representa também uma nova leva de desafios para os criadores cênicos. Diante de manifestações, protestos e denúncias que se tornarão cada vez mais presentes, pensar novas formas de representação que englobem também as minorias se mostra como uma tarefa complexa, incerta e desestabilizadora, mas também imprescindível para aqueles que desejam produzir um teatro que se manifesta em diálogo com as demandas e transformações de uma sociedade em evolução.

\section{Referências}

AZEVEDO, José Fernando Peixoto. Eu, um crioulo. São Paulo: N-1 Edições, 2018.

BELTING, Hans. Bild Anthropologie. Munich: Wilhelm Fink Verlag, 2001.

BORGES, Rosane. Das perspectivas que inauguram novas visadas. In: HOOKS, bell. Olhares negros: raça e representação. São Paulo: Elefante, 2019.

CORNAGO, Óscar. Ensayos de teoría escénica: sobre teatralidad, público y democracia. Madri: Abada Editores, 2015.

CRISTINE, Danielle. Entrevista II. [mai. 2019]. São Paulo, 2019. 1 arquivo .mp3 (31:09 $\min$.). 
DIÉGUEZ, Ileana. Cenários liminares. Teatralidades, performances e política. Uberlândia: EDUFU, 2016.

FADEL, Georgette. Entrevista I. [mar. 2019]. São Paulo, 2019. 1 arquivo .mp3 (39:15 $\min$.).

FÉRAL, Josette. Além dos limites: teoria e prática do teatro. São Paulo: Perspectiva, 2015.

FERNANDES, Sílvia. "Experiências do Real no Teatro". Sala Preta, v. 13, São Paulo, ECA-USP, 2013.

HOOKS, bell. Olhares negros: raça e representação. São Paulo: Elefante, 2019.

LIMA, Evani Tavares. "Teatro negro, existência por resistência: problemática de um teatro brasileiro”. Repertório, Salvador, n. 17, p. 82-88, 2012.

MBEMBE, Achille. Crítica da razão negra. São Paulo: N-1 Edições, 2018.

SÁNCHEZ, José A. Practising the real on the contemporary stage. Bristol: Intellect, 2014.

SCHUCMAN, Lia Vainer. Entre o encardido, o branco e o branquíssimo: branquitude, hierarquia e poder na cidade de São Paulo. São Paulo: Annablume, 2014.

Recebido em: 03/07/2020

Aprovado em: 23/11/2020 